\title{
The Internet: A new agora?
}

\author{
Niklas Damiris* and Helga Wild** \\ *Apple Research Labs/Stanford University \\ 942 College Avenue, Palo Alto CA 94306, USA \\ Phone: +14154937570 \\ Email: niklas@leland.stanford.edu \\ ** Institute for Research on Learning \\ 66 Willow Place, Menlo Park, CA 94025, USA \\ Phone +1 415614 7933, Fax: +14156147957 \\ Email: helga_wild@irl.org
}

\begin{abstract}
Democracy in ancient Greece relied on the active participation of the people in political life. This participation took the form of speech and action, and was supported by a certain configuration of space, the agora, and a certain configuration of community, the polis. Subsequent developments, specifically the gradual rise of the economic and the parallel dismantling of the public sphere deeply affected the balance that these factors had achieved in the Greek city-state. Most importantly, they obscured the grounding of the political discourse in space and community. As a result, democracy today has come to be associated with abstract institutions and governance mechanisms.

The Internet appears to offer new hope for a participatory kind of democracy. This is due to a rich potential for communication and an almost unlimited access to information. However, to fulfil this hope it needs to reestablish the balance between the two axes, the discursive-performative - speech and action, and the embodied - space and community.
\end{abstract}

\section{ROOTS OF DEMOCRACY IN ANCIENT GREECE}

Ancient Greece is, if not the cradle of western civilization, certainly the cradle of western democracy. Democracy took root with the foundation of the Greek citystate and its specific form of political organization, the polis. 
According to Hannah Arendt in The Human Condition (Arendt, 1958), this was accomplished by a differentiation of the social sphere into two separate realms: the realm of the house (oikia) made up of family, kin and slaves, which could be called the realm of the private since it was under the authority and control of the master of the house, and the realm of the political embodied in the agora whose institution and architecture supported people engaged in public debate.

If historians are right, the public realm of the Greek city-state was built at the expense of private social organization. It replaced in importance earlier forms of organization dependent on family and kinship. Indeed, for the citizen-members of the polis, the household existed in order to support their political life. The agora constituted the sacred space of public life. The hearth with its gods and goats, in turn, functioned as the sacred space of the household. Agora and oikia supported and complemented one another.

The material production of subsistence centred around the household. The familial existence included slaves, who contributed to the everyday life of housekeeping and were thereby also bound by the laws of the house: literally, the meaning of economy. The process of material production offered the opportunity to accumulate money through hard work and was open even to slaves. Yet, even though making money was considered legitimate, it was not in itself pertinent to the duties and powers associated with being a participating member of the agora.

If only the master of the household had the right to participate in public affairs this was because he was entitled to a viewpoint, that is, he had the right to offer his opinion in the agora as one among equals, and he had a standpoint, that is, an existentially grounded place through his position in the household ${ }^{1}$.

Being well off was therefore a necessary, but not a sufficient, condition for being a citizen of the Greek polis. 'To live the good life,' as Aristotle called the public life of the citizen (McKeon, 1941) meant that one had to strive not merely to free oneself from the hardship of making a living without indemnity. Once that had been accomplished one was condemned to the freedom of participation in the public life which was itself equivalent to a full-time job. No one who had to labour could participate in the time-consuming activities of the polis.

One could imagine that those who could afford not to work might have wanted to enjoy a quiet life at home instead of doing politics. But, no matter how comfortable private life in the household could become for Athenians, it could never be more than a supplement even where it offered room for activities which a large number of people today would rank higher than political engagement. The reason for this was that the political life of the agora did not merely impart a better or nobler character to ordinary life. Rather, the agora constituted human life as a novel and autonomous form. The member of the polis had the potential to be good because, as Hannah Arendt states, 'by having mastered the necessities of sheer life, by being freed from labor and work, and by overcoming the innate urge of living creatures for their own survival, [he] was no longer bound to biological life processes' (Arendt, 1958, p. 37). 


\section{AGORA: PLACE OF ETHICAL CONDUCT}

The agora was the physical place that embodied the unique character of Greek democracy. It afforded the community of free and equal men (the polis) the opportunity to engage in dialogue with one another without consideration of power, wealth, and heritage. This is where they would engage in daily intense interaction and debate and decide about the common good of the city-state. In the agora, all men were free and equal and no-one was either ruling or being ruled. In this respect, the space of the agora established its own set of rules for ethical conduct. Decisions were made by consensus, without force. Hierarchy and violence had no place in the agora; they were bound up with the realm of necessity and belonged therefore to the household.

The concern of the polis was to make the world appear as fully as possible by enabling every free man to take a stance. That meant that the agora saw both conflict and consensus expressed and developed. It was the duty of every participant to speak as best he could to the course and consequence of possible actions and to move his fellow men to follow him in the proposed direction. The only way in which individuals could stand out in their fellow citizens' esteem, was through important and heroic political action. This space of social appearance was established both through action in the political disputes of the agora and through action in war.

Engaging in political life was the highest form of life since it made man become properly human. Aristotle, in his definition of man as the zoon politicon (the political animal) and in the corollary definition of man as zoon logon ekhon (a living being capable of speech), makes clear how the Greeks distinguished man from animal precisely through the former's participation in political life.

Consequently, of all the activities habitually engaged in by the ancient Greeks, the two valued most highly were the ones considered constitutive of political life: action and speech. This included the possibility of action through speech, namely when one managed to utter the right words at the right moment (Arendt, 1958, p. 25). One can find here the origin of the place of rhetoric as the cornerstone of the educational curriculum of the Middle Ages.

To sum up the lessons from the Greek city-state for current purposes, neither individual autonomy nor being social alone was enough to guarantee democracy. The individual self embedded in the household and the family, and thereby in some form already socialized, could only develop a one-sided view of the world. The world was fully disclosed only in the political realm in which people confronted the embodied stance of others and no-one's identity was subjugated. Being social was, therefore, not equivalent to being political. While it allowed the citizen to cope with the problems associated with work and with labour, first, through cooperation in the household and, later, through competition in the market, it did not generate a political life. This required taking an ethical stance with respect to the needs of the community and taking action for the common good. Performance in the agora expressed itself through speech and action. These were grounded in the physical space and enabled by the community; space and community, in turn, were transformed by political performance into a place of ethical conduct and a polis of heroic individuals. 


\section{TRANSFORMATION OF THE PUBLIC AND PRIVATE SPHERE}

Since the Greek polis, Europe has seen a great deal of change in the function and meaning of private and public realm. Ancient Rome, with its form of civic society, elevated its members to the status of citizen-soldier whose duty was to contribute to the expansion and ruling of the Roman empire. The household continued to be the place of labour, production, and economic considerations. Its value-adding function became recognized in the legal conception of private ownership.

In the feudal order of the Middle Ages, monetary and trade concerns became legitimated as motivating factors behind political ambition. With this development, the household's preoccupation with exchange and possession of the products of work started to invade the public realm. One result of this invasion was literally the transformation of the public place of political life into the marketplace where commodities were traded and exchanged for money, a development which marks the beginning of the era of capital accumulation.

By the time of the great monarchies in Europe, the economic way of thinking had embedded itself deeply into the public sphere. With the rise of state power and stately institutions, 'private' acquired the meaning of operating in a non-official function or of being excluded from public office. Later, with the rise of capitalism, this meaning of privacy took on a positive and economic flavour and privacy became associated not only with the house and family circle but also with the domain of persons acting in their private economic interests, thereby establishing a market functioning outside the rules of state institutions.

The privacy and autonomy of the household were secured through the competition of private individuals in the free market. The financial success of this new structural arrangement produced a value shift: as the private realm gained in importance it became the defining criterion of what it meant to be human. The new private self with its beliefs and opinions demanded its own public expression. This resulted in the creation of a second public sphere alongside the sphere of state institutions, that of public opinion. Salons in France, coffee houses in England, and Tischgesellschaften in Germany, provided the place for the formation of this public opinion while the educated bourgeois family provided the community (Habermas, 1991).

'The public sphere as a functional element in the political realm was given the normative status of self-articulation of civil society with the state authority corresponding to its needs. The social precondition for this "developed" bourgeois public sphere was a market that, tending to be liberalized, made affairs in the sphere of social reproduction as much as possible a matter of private people left to themselves and so finally completed the privatization of civil society' (Habermas, 1991, p. 74).

The state eventually accepted civil society as a carrier of truth and saw itself as providing the mechanisms for implementing it. For a while, state institutions and public opinion functioned cooperatively. But, as the bourgeois family became more and more a site of consumption, the public spaces, salons, coffeehouses, etc., that enabled the debates formative of public opinion, lost their grounding in the community. They either transformed themselves into capitalist enterprises (newspapers and other publishing businesses) which operated under the law of the 
market or turned into islands of aesthetic and intellectual life with little impact on the world beyond.

In the twentieth century, the interaction between public and private sphere has become the uneasy coexistence of welfare state and individual and human rights. It is clear that this is the result of a development long in the making. The commons which used to be dominated by cultural matters was gradually overtaken by the economic preoccupation of possessive individualism. This has led to the assimilation of the concern for the public good by the economic rationale now reinterpreted as the problem of free riding or, alternatively, to what has come to be known as 'the tragedy of the commons' (Hardin, 1982).

Democracy has ceased to be concerned with the creation and support of a public sphere in which people articulate their differences and develop common goals and courses for action. Democracy has become synonymous with the legal institutions and financial governance mechanisms that protect states and individuals from each other in the race for economic growth.

\section{DEMOCRACY AND THE INTERNET}

With the triumph of the 'economics-first' ideology, all technology invented since the advent of capitalism has been justified as a means to added growth. Technological innovations, like the steam engine or the car, made this glaringly obvious. They dramatically changed people's standard of living, economically understood, and literally transformed the face of the earth. Enter now a new technology - networked computers - and something different seems to be in the offing! Or is it?

In the United States today, policy experts hail the Internet as the hope for democracy. They claim that it provides a cure against the decreased participation in the political process, the disproportionate influence of a few powerful interest groups, the biased reporting in the media, and the general disaffection of the voter. The Internet can overcome, or at least improve, this situation, they argue, because it gives easy and unlimited access to information, empowers the ordinary citizen through giving ownership of the textual means of production, and makes communication among equal-minded spirits and participation in the political process so much easier, so much cheaper (Corrado and Firestone, 1996).

On the downside, they note the danger of splitting the population into those with access to the Internet and those without; not an unreasonable fear in the light of the growing impoverishment of the middle class in the United States. And there exists always a dark side to the advantages mentioned above: information is useless when one either cannot find it or one finds too much. If interest groups can influence government and media, what is to prevent their censoring influence on the Internet? Already the technologies behind the Internet are controlled by fewer and fewer companies. And economic interests invade the Internet much as they have invaded all other domains of life.

Yet the dream of a place where people could freely express their individuality and still be part of a community, much in the spirit of the agora, is very much alive on the Internet (though, as Frank Zappa said about jazz, it smells a bit funny (Zappa, 1978)). When hearing the founders of the WELL (the Whole Earth 
'Lectronic Link) recount their vision of computer-mediated communication, one notices immediately their eagerness to associate it with a domain free of commercial interests and free of government intervention too, for that matter. Like the ex-hippies many of them are, they try to imagine a world where people would be freely sharing information, ideas, and software without concern for property rights, profits, and the like.

In the year 1997, most of that sounds like an impossible wish list, since business interests are powerfully setting the agenda for a utilization of the Internet different from the one originally envisioned. Interesting enough, many of the hippie founders do not seem averse to electronically conducted commerce even though they use libertarian rhetoric to rail against governments' attempts to regulate the Internet $^{2}$. So, here we find under different guise a repetition of the old tension between self-interest, on one side, and impersonal institutions and regulations, on the other. Trying to understand the potential of the Internet for envisioning democracy has become a challenging task indeed!

The conception of democracy fostered by economic liberalism seems far removed from the agora understood as a public place with established rules of conduct where people freed from economic worries debate their differences, develop their identities, and realize common goals. And yet, there is no denying that the Internet, which is still in its fledgling stages, offers some support for the vision of a sphere where the participants could communicate widely, organize, and coordinate their activities. The question becomes then, how one could go about realizing this hope so that it can eventually transform the housekeeping mentality instead of succumbing to it?

Possibly we can get a first glimpse of an answer from the Internet itself, from the way people have envisioned and used it. Interestingly enough, the Internet has been described from its inception alternately as a community or as a space of sorts. One is tempted to see this as a poetic reimagining of one of the main axes of Greek democracy: space and community. We will discuss each one of these metaphorical takes briefly in turn.

\section{INTERNET AS VIRTUAL COMMUNITY}

The journalist Howard Rheingold, summarizing many peoples' notions of the Internet, calls it - following McLuhan - a 'virtual village' where folks would use words on screens to exchange pleasantries, engage in intellectual discourse, conduct commerce, and create art and a lot of talk. According to Rheingold, computer-mediated communication was an outpost of social habitation best characterized as an ongoing conversation conducted among people who started as complete strangers but who became over time more and more involved in each others' concerns. Computer-mediated social groups, he claims, were virtual communities: their creation and sustenance required an act of imagination. However, he also adds: 'The WELL felt like authentic community to me from the start because it was grounded in my everyday physical world. Wellites who don't live within driving distance of San Francisco Bay [which is where Rheingold resides] are constrained in their ability to participate in the local networks of face to face acquaintances' (Rheingold, 1993). 
We can summarize the Internet-as-community metaphor thus: networked information technologies enables people to produce speech genres (Bakhtin, 1984) or phrase regimes (Lyotard, 1988). This means self-regulated, rule-governed enclosures in a generalized system of communication created by like-minded people, in this specific case, through electronic means. According to this vision, to be is to communicate: people 'talk-write' with the expectation of an interlocutor in mind who is preparing a response, offering agreement, sympathy or objection. The narratives of different lives become thereby intermeshed and engender new social relations and contact with people one could not otherwise encounter.

This brings communication close to being equivalent to community. Or rather, the meaning of the term 'community' receives a reinterpretation because of the way it gets used on the Internet. People speak about communities of transaction, communities of interest, communities of relationships and communities of fantasy, depending on whether one buys or sells via the Internet, discusses specific topics, works through dramatic personal events, or engages in make-believe games. Insofar as we focus on the communicative exchange aspect of community, it is to some extent justified to see the Internet as a new kind of soil which nourishes new types of community. But, as always, economic interests are also at work here. Already, these so-called communities are being advertised as fertile ground for new and emerging markets (Armstrong and Hagel, 1996), which makes one wonder whether the Internet is not employing the term 'community' in a rather euphemistic fashion.

$\mathrm{Be}$ that as it may, the practices on the Internet make clear that the communities fostered there are always the product of the discursive exchanges of the participants, not - as is the case outside the Internet - their ground.

\section{INTERNET AS VIRTUAL SPACE}

The community metaphor brings to mind communication and social relations; the conception of the Internet as space capitalizes on the spatial metaphors that abound in language which can be traced back to a person's ability to act on and move in its environment. The issue raised is this: as an information environment becomes increasingly persistent and perceptible does this not imply that there is 'a there there', to borrow Gertrude Stein's expression (Stein, 1933)? Or, that one can produce a there by the manipulations the Internet affords?

If we consider the production of space through human agents we have to introduce the tripartite distinction of space made by Henri Lefebvre. He suggests that there are three kinds of spaces for humans: a linguistic mental space (the conceived), a physical space (the perceived) and the space of social practice (the lived) (Lefebvre, 1991, p. 40). In contemplating the appropriateness of the spatial metaphor for the Internet we need to remain aware of the complexity of our normal experience of space. What is it that makes us experience space: our perception of three-dimensionality of objects, our reliance on permanent features of the environment, or our physical movements in it? How does this relate to the sense of place which is much more grounded in pragmatics of action and the temporality of the body? 
To be sure, on the face of it, the Internet is pretty anti-spatial: the fundamental principle of data independence holds that a user should be able to obtain something without knowing where or how it is stored. This is the whole idea with the Internet. The fact that some items may refer to physical locations does not mean that the Internet is one of those. No distance, no continuity, no ordering! Yet, places can exist without space, as low bandwidth virtual reality environments like multi-user dungeons (MUDs) have shown.

Researchers in the area of computer-supported work have by now realized the difference between space and place. They claim that it is place that makes possible the framing of appropriate behaviour, and find that framing of behaviour on the Internet, though often organized around spatial features, nevertheless operates quite independent of them. In this fashion they reveal - after lengthy discussion - the derivative nature of the Internet's spatiality by putting the emphasis on place without space (Harrison and Dourish, 1996).

Thus, analogous to Internet communities, space too turns out to be the effect of actions taken, not their starting point. Appropriately framed behaviour creates an enclosure within the Internet which gives the participants a sense of place and this place, in turn, can be demarcated by visual clues and equipped with spatial features.

\section{SPEECH AND ACTION}

After this excursion into metaphors for the Internet, we can fully appreciate the meaning of virtuality as it is applied to both community and space. Community and space are called virtual on the Internet because they are effects, namely the effects of the discursive activities and the communicative interactions which the Internet affords. They are not grounding, but grounded, and thereby acquire a flavour of self-presentation.

Surprisingly, Arendt, in speaking about democracy, anticipates such a development with these remarks which sound like early advertisement for the Internet:

'Action and speech create a space which can find its proper location almost anytime anywhere. It is the space of appearance in the widest sense of the word, namely the space where I appear to others as others appear to me, where men can exist not merely like other living or inanimate things but make their appearance explicitly' (Arendt, 1958, pp. 198-199).

Arendt suggests that the joining of speech and action can create a space in which people can appear to one another. If we identify speech in ancient Greece with communication on the Internet - which is defensible if we take into account the transformation that a novel medium will impose - we are still falling short of the action: what would it take to make the Internet into a space for social action?

Here is a pertinent quotation from Habermas in which he justifies the need for a level of action higher than the instrumental goal-oriented one that underwrites normal activities. This higher level of action, which he calls 'communicative action' (Bernstein, 1995, p. 42), is what enables people not only to enter the space of appearance mentioned by Arendt but also to develop consensus among themselves - a necessary component of democratic practice. Communicative action 
depends on a language system which is appropriate to the needs of a community and is revisable if those should change.

'The consensus-producing power of argument rests on the supposition that the language system in which the recommendations requiring justification, the norms, and the generally accepted needs cited for support are interpreted, is appropriate ... We call appropriate that language of morals which permits determinate persons and groups, in given circumstances, a truthful interpretation both of their own particular needs, and more importantly of their common needs capable of consensus. The chosen language system must permit those and only those interpretations of needs in which the participants in the discourse can make their inner natures transparent and know what they really want ... By virtue of its formal properties discourse must guarantee that the participants can at any time alter the level of discourse and become more aware of the inappropriateness of traditional need interpretations; they must be in a position to develop that language system which permits them to say what they want under given conditions with a view to the possibility of changing conditions, and to say - on the basis of a universal consensus - what they ought to want' (Habermas, quoted in McCarthy, 1978, p. 316).

If, in other words, communicative action is to take place, the language system into which all participants enter has to be appropriate for the expression of their true wants and needs. While the Internet can be seen as providing the conditions for communication and, consequently, for action - not through speech but through communication - the appropriateness of the language system and the ensuing behaviour cannot be judged from within the Internet. It takes its validity from a 'needs interpretation' derived from the real world. From there, comes also the demand for a change in the language system and its norms for appropriate behaviour if a group of persons is not allowed proper self-presentation under the current one.

The connection to space and community outside the language system is made via the embodiment of the communicative actor and the materiality of the medium itself. The connection appeared, though obliquely, already in Rheingold's discussion of the WELL. He writes, 'People in virtual communities do just about everything people do in real life, but we leave our bodies behind.' But then he also observes, 'Wellites who do not live within driving distance of San Francisco Bay are constrained in their ability to participate ...' Although we do not equate face-toface relations with political behaviour, they certainly are the ground for ethical conduct and are thereby intimately connected to the language of morals and to what counts as appropriate behaviour on the Internet (Levinas, 1981).

The only way the Internet can help further democratic ideals is then by tying itself closer to the world outside. This world is never really outside, but all too often cut off deliberately by a dualistically inspired desire to leave the body and all other aspects of the material world behind. Such bracketing of the real world leads ultimately to an impoverishment of the exchanges on the Internet itself. 


\section{CONCLUDING REMARKS}

To sum up our thoughts on the possible use of the Internet for reestablishing political life: two main axes are necessary in establishing the basis for a participatory democracy; one stands out in explicit behaviour; the other forms the background from which the first emerges. The first axis is that of speech-and-action which appears to be one of the strengths of the Internet. The other axis is that of space-and-community which the Internet has forgotten or suppressed, and has attempted to substitute with virtual counterparts. Needless to say, we feel the substitute works at best as a reminder of the real thing, at worst as the wishful thinking of a dualistic mind. The grounding of democratic political life in space and community does not lose its relevance by being paraded in effigy on the Internet.

Lest we want to treat the creation of the Internet as culmination and institutionalization of the Cartesian schism, we must instead strengthen the relation of the Internet to the larger world and its impact on it. The challenge is to develop an understanding that does justice, first, to the self evident (and, hence, unknown) character of embodied existence and its connection to community and space. And second, this alternative world view must try to imagine not virtual communities and spaces made of words, but develop the affordances of a medium whose materiality is continuous with human embodiment. The way to this goal would also lead to a better understanding and novel use of information technology.

Following Spinoza, understanding bodies means attending to their ethics. This is very important and also relevant for grasping the sense in which the accomplishment of Athenian democracy was not only the creation of superior rationality and rhetorical skill but, most of all, the result of ethical conduct. The capacity for rationality and ethical conduct are related, but they are not interchangeable. Currently, the state of technology and the social imaginary of the culture support mainly discursive rationality. The aspect concerning the ethical remains underdeveloped. Or, to put it differently, by separating speech and rhetoric from their relation to embodied existence, technology has robbed itself of the opportunity to affirm the immanence of life. The current design of the Internet does not support embodiment and the ethics it entails. The aim of this paper is to inspire people to work on one that does ...

\section{REFERENCES}

Arendt, Hannah. The Human Condition. Chicago Press, 1958.

Armstrong, Arthur; Hagel, John. The Real Value of ON-LINE Communities. Harvard Business Review. May-June 1996.

Bakhtin, Mikhail. Speech Genres and Other Essays. University of Texas Press, 1984.

Bernstein, Jay M. Recovering Ethical Life. Jürgen Habermas and the Future of Critical Theory. Routledge 1995.

Corrado, Anthony; Firestone, Charles M., Editors. Elections in Cyberspace: Toward a New Era in American Politics. The Aspen Institute, 1996.

Damiris, Niklas. Light and The Physics of Intentionality. Under review.

Electronic Dark Ages, San Francisco Guardian. October, 1996.

Habermas, Jürgen. The Structural Transformation of the Public Sphere. An Inquiry into a Category of Bourgeois Society. Translated by Thomas Burger, MIT Press, 1991. 
Hardin, Russell. One for All. The Logic of Group Conflict. Beacon Press, 1982.

Harrison, Steve; Dourish, Paul. Re-Place-ing Space: The Roles of Place and Space in Collaborative Systems, Proceedings of the ACM Conference on Computer-Supported Cooperative Work CSCW '96, Boston, Nov. 1996.

Lefebvre, Henri. The Production of Space. Blackwell, 1991.

Levinas, Emmanuel. Otherwise than Being or Beyond Essence. Martinus Nijhoff, 1981.

Lyotard, Francois; The Differend. Minnesota Press, 1988.

McLuhan, Marshall. Understanding Media: The Extensions of Man. McGraw-Hill, 1964.

McCarthy, Thomas; The Critical Theory of Jürgen Habermas. MIT Press, 1978.

McKeon, Robert, Ed., Basic Works of Aristotle. Random House. 1941.

Rheingold, Howard. The Virtual Community. Vintage, 1993.

Spinoza, Baruch. Ethics. Dover Edition. 1670.

Stein, Gertrude. The Autobiography of Alice B. Toklas. Harcourt, Brace and Co., 1933.

Zappa, Frank. Roxy \& Elsewhere. LP. 1978.

For the differentiation between viewpoint and standpoint, see Damiris (forthcoming).

See a pungent critique of this attitude in Electronic Dark Ages, San Francisco Guardian, October 1996. 